\title{
What is your diagnosis?
}

A 20-year-old primigravida was referred due to increased risk of trisomy 21 in the triple test result at 21 weeks of gestation, which was $1 / 59$. Sonographic examination revealed hypoplastic nasal bone $(\mathrm{NB}=4.3 \mathrm{~mm})$ and hyperechogenic bowel with mildly dilated segments (bowel diameter $=4.5 \mathrm{~mm}$ ) (Figure 1). Past medical histories of both parents were insignificant. There was no consanguineous marriage. Amniocentesis was performed. Quantitative fluorescence polymerase chain reaction (PCR), karyotype, and cystic fibrosis panel were normal. Due to hyperechogenic bowel and mildly dilated segments of the bowel, close surveillance was planned. At 24 weeks and 25 weeks, these segments of the bowel continued to dilate and increased to $9.8 \mathrm{~mm}$ and $11.2 \mathrm{~mm}$, respectively. At 25 weeks of gestation, anorectal complex was observed intact. Dilatation of the bowel progressed and reached to $23.8 \mathrm{~mm}$ at 29 weeks of gestation, which was also coincided with an increase in the amount of amniotic fluid (Figure 2). Besides dilated bowel segments, a cystic structure with hyperechogenic inner fluid than the other dilated bowel segments had become noticeable during the examination at 29 weeks. Due to the risk of volvulus, weekly follow-up visits were scheduled. From 29 to 37 weeks, the size of the cyst and amount of amniotic fluid continued to increase, although the diameter of the dilated bowel remained relatively stable (Figure 3). Within last 4 weeks before delivery, in addition to the cyst and bowel dilatation, ascites began to accumulate in the fetal abdomen. In this period, Doppler of the middle cerebral artery and umbilical artery remained normal, however a-waves in the ductus venosus started to deepen and fetal ascites progressively increased. We, therefore, decided to perform paracentesis via ex utero intrapartum treatment (EXIT) procedure in the intrapartum period. At 37 weeks, planned cesarean under deep general anesthesia was performed. Male infant weighing $2910 \mathrm{~g}$ was delivered. Umbilical cord was not clamped, and oxytocin administration was withheld. Newborn was laid between the mothers legs. Under the ultrasound guidance, paracentesis was performed and $240 \mathrm{~mL}$ of green fluid was aspirated, which effectively ruled out hemorrhagic ascites. The newborn was neither intubated nor required mechanical ventilation, and after a brief stay in the neonatal intensive care unit, he was operated. After an uneventful postoperative course, he was discharged. At 2 years of age, he was faring well.
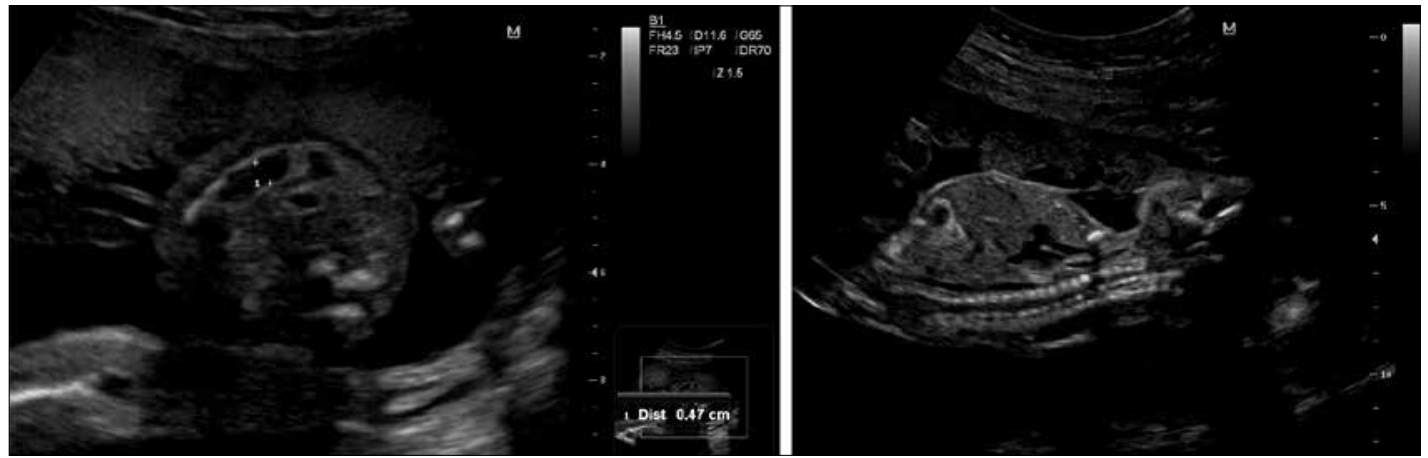

Figure 1. Hyperechogenic and dilated bowel loops at 21 weeks gestation

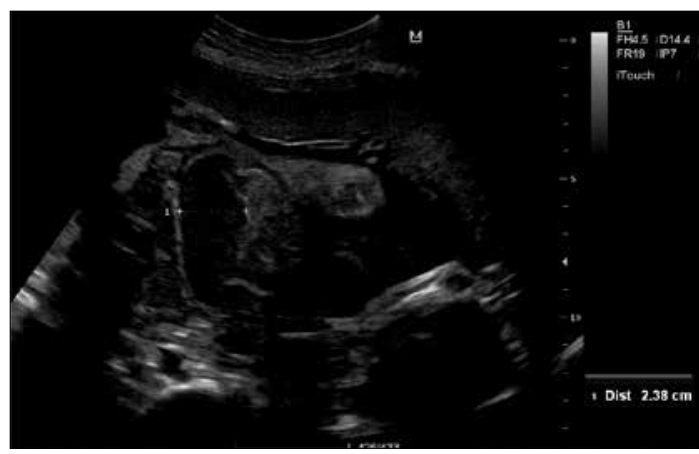

Figure 2. Dilated bowel at 29 weeks of gestation

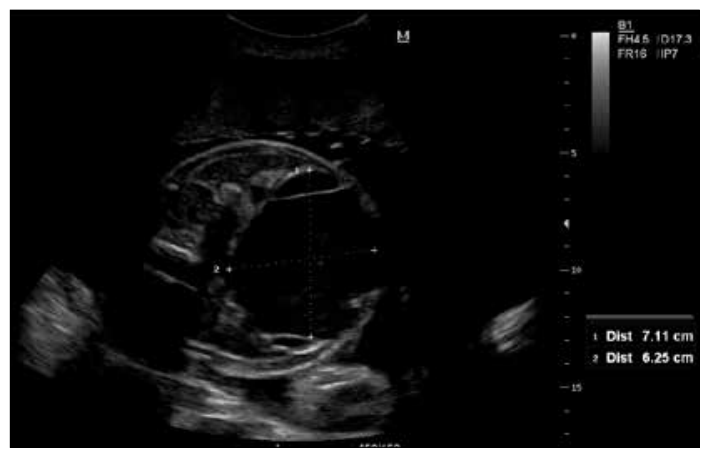

Figure 3. Cystic structure at 34 weeks of gestation 


\section{Answer}

Intra-operative findings and pathological examination of the specimen revealed diagnoses of ileal atresia, intestinal perforation, intestinal malrotation, Ladd band, and intestinal duplication cyst, which overlap with the prenatal ultrasound findings. Incidence of intestinal obstruction in the neonatal period is around 1/2000 (1). Causes include duodenal atresia/stenosis, malrotation and midgut volvulus, intestinal atresia, meconium ileus/peritonitis, and, last but not least, enteric duplication cyst. Each of these underlying pathologies has varying incidences and frequently accompanied with another pathology. Incidence of malrotation has been estimated to be around 15:1,000,000 in children less than 1 year old (2). Associated abnormalities can be found in $30-60 \%$ of the malrotation cases, which include intestinal atresia and obstruction, Meckel diverticulum, intussusception, Hirschsprung's disease, anorectal malformations, mesenteric cysts, anomalies of the extrahepatic biliary system, cardiac anomalies, and trisomy 21 (2, 3) (4). However, intestinal duplication cysts rarely coincide with malrotation (5). We systematically searched PubMed from inception through January 2016 to discover relevant cases of intestinal malrotation and intestinal duplication cyst that were prenatally diagnosed, followed up, and managed in the immediate postpartum period. In order to achieve this, we had used the first query in Table 1 . This query yielded seven results among which only one was relevant (5). This related article had reported diagnosis and management of a 2-year-old boy (5). Accordingly, and to best of our knowledge, prenatal diagnosis, follow-up, and management of malrotation with intestinal atresia/perforation and accompanying intestinal duplication cyst have not been reported in the English literature.

With the second, third, and fourth queries in Table 1, we systematically searched the literature for the antenatal ultrasonographic signs of fetal intestinal malrotation and volvulus, meconium pseudocyst, and intestinal duplication cyst, which may help in differential diagnosis. Differentiation of volvulus from a duplication cyst and meconium pseudocyst may be of utmost importance because of the life-threatening complications of the former pathology. Imaging findings for malrotation and volvulus included midline stomach, small bowel on right side of the midline, classic mesenteric whirlpool sign (twisted mesentery around the mesenteric vascular stalk), coffee-bean sign, and three parallel fixed bowel loops on transverse scan (4, 6-8). Reported imaging findings for intestinal duplication cyst included thin- or thick-walled cystic structure, double wall appearance/sign, pseudo-double bubble appearance, abdominal cyst with peristalsis, echogenic mesenteric tissue consisting of fat close to the cyst, and intra-cystic echogenic contents (9-12). Reported characteristics of meconium pseudocyst included thick membrane containing multiple calcium deposits and plaques (13). Although it is hard to differentiate duplication cyst from a meconium pseudocyst, malrotation and volvulus can be differentiated from the former two according to the reported ultrasonographic findings. From clinical standpoint, the diagnosis of volvulus is imperative, because if not treated surgically within 6 hours, it may cause necrosis of the entire small bowel and right colon (7). In this context, Doppler examination and effort to demonstrate mesenteric whirlpool sign should be attempted in every case in doubt. However, there will always be cases where we cannot reach a definitive diagnosis, and close follow-up of these cases with serial ultrasound scans and fetal well-being evaluation are clearly required. Fetal demise in case of volvulus occurs secondary to bowel infarction, hemorrhagic ascites, and fetal anemia $(14,15)$. Accordingly, to predict fetal demise secondary to hemorrhagic ascites, middle cerebral artery Doppler and non-stress testing becomes critical $(14,15)$. Increased peak systolic velocity in middle cerebral artery Doppler examination shows anemic condition of the fetus secondary to bowel infarction and hemorrhage. In cases with abnormal fetal heart rate pattern and ascites for which the diagnosis cannot be established, in utero paracentesis may provide both diagnostic information and treatment benefit in terms of correcting abnormal fetal heart rate pattern (16). In utero paracentesis may also facilitate vaginal delivery by preventing dystocia via decreasing fetal abdominal distention (16). Moreover, in utero paracentesis may reduce respiratory compromise after birth (16). For the identification of hemorrhagic change in the bowel wall, combined use of ultrasonography and ultrafast magnetic resonance imaging was also reported (17). On T2-weighted single-shot fast-spin echo magnetic resonance images, enlarged loops that exhibit a lower signal intensity than the surrounding bowel loops suggests bowel infarction and intraluminal hemorrhage (17). When the middle cerebral artery Doppler indicates anemic fetus or in utero paracentesis shows hemorrhagic ascites emergency in utero transfusion may be required (15). In the overlooked cases, when fetus escapes the sudden insult and the condition becomes relatively chronic, hemorrhagic volvulus may result in fetal hydrops $(15,18)$.

For the previously mentioned benefits and indications of in utero intervention, paracentesis may also be performed safely in the immediate intrapartum period as an EXIT procedure as in the current case. The first EXIT procedure was utilized for a fetus with cervical teratoma to secure the airway with bronchoscopy for 10 min (19). In the subsequent attempts of the EXIT procedure, it was noticed that when the fetus was completely delivered, the volume of the uterus decreased significantly; as a result, placental circulation can only continue for a short duration of time $(20,21)$. With further attempts, durations of 20-60 min were obtained when the fetus was partially delivered (22). Due to the short duration of time required by the paracentesis procedure, intervention can be easily performed after complete delivery of the fetal body. Tense ascites, enlarging abdominal organs or structures, and secondary abdominal distention impact the fetal thoracic structures, which can adversely affect the neonatal respiratory functions. As in our case, intrapartum paracentesis via the EXIT procedure under ultrasonographic guidance can be easily and safely performed to relieve pressure on diaphragm and to ensure stable neonatal respiratory functions which may be important in a newborn awaiting surgery. Avoiding mechanical ventilation during this critical period is imperative for these fragile newborns which can deteriorate quickly. In addition, aspiration of green bile colored fluid during paracentesis can rapidly rule out hemorrhagic ascites secondary to bowel infarction and establish diagnosis of bowel perforation in this critical transition period.

\section{Conclusion}

In cases of fetal bowel obstruction with increased abdominal pressure secondary to meconium peritonitis, ascites and/or enlarging duplication cyst paracentesis can be utilized either in utero or ex utero. When utilized in the immediate intrapartum period para- 


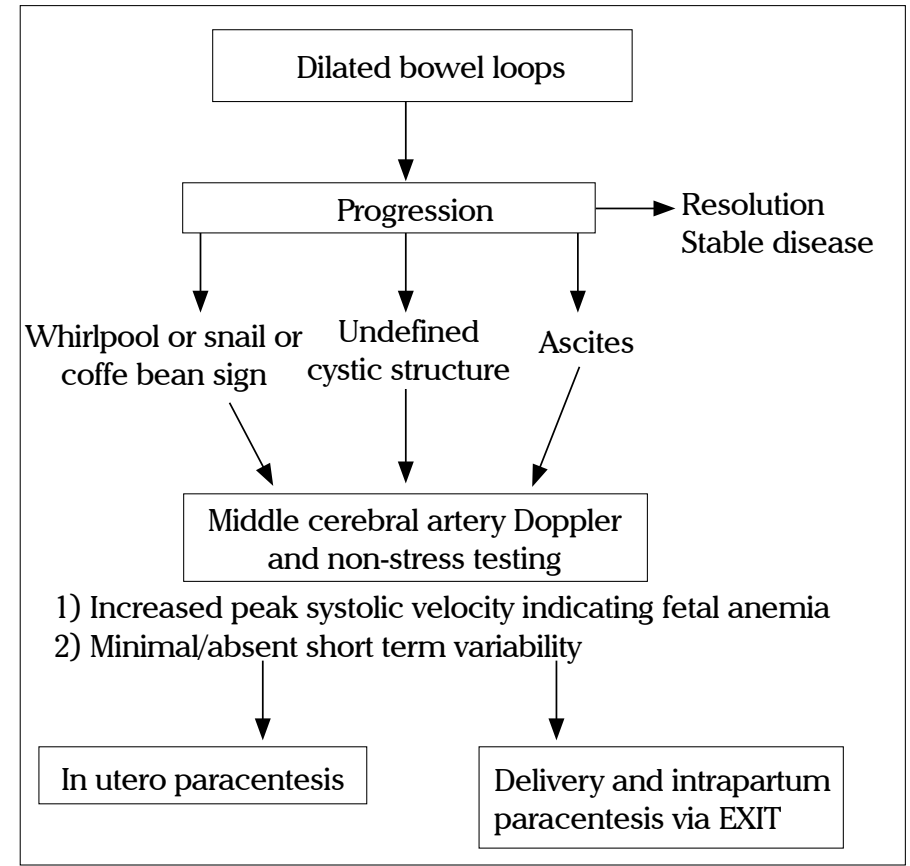

Figure 4. Antenatal management of fetal bowel obstruction

centesis can be safely performed via the EXIT procedure to prevent deleterious effects of the abdominal distention on the respiratory functions of the newborn and provide fast and reliable diagnostic information. Based on the available relevant literature a management algorithm is proposed for this very specific patient group (Figure 4). When ultrasound indicate hyperechogenic bowel and dilated bowel segments, we should keep mind that $53 \%$ of those will have an abnormality after birth (23). Consequently, antenatal follow-up and postpartum close surveillance of these fetuses should continue.

\section{Ahmet Başaran, Mustafa Başaran \\ Department of Obstetrics and Gynecology, Konya Training and Research Hospital, Konya, Turkey \\ References}

1. Shawis R, Antao B. Prenatal bowel dilatation and the subsequent postnatal management. Early Hum Dev 2006; 82: 297-303. [CrossRef]

2. Teitelbaum DH, Wulkan ML, Georgeson KE, Langer JC. Intestinal Rotation Abnormalities. In: Zeigler MM, Azizkhan RG, von Allmen D, Weber TR, editors. Operative Pediatric Surgery. Second edition ed: McGraw-Hill; 2014. p. 540.

3. Adams SD, Stanton MP. Malrotation and intestinal atresias. Early Hum Dev 2014; 90: 921-5. [CrossRef]

4. Yoo SJ, Park KW, Cho SY, Sim JS, Hhan KS. Definitive diagnosis of intestinal volvulus in utero. Ultrasound Obstet Gynecol 1999; 13: 200-3. [CrossRef]

5. Somuncu S, Cakmak M, Caglayan E, Unal B. Intestinal duplication cyst associated with intestinal malrotation anomaly: report of a case. Acta Chir Belg 2006; 106: 611-2. [CrossRef]
6. Uerpairojkit B, Charoenvidhya D, Tanawattanacharoen S, Manotaya S, Wacharaprechanont T, Tannirandorn Y. Fetal intestinal volvulus: a clinico-sonographic finding. Ultrasound Obstet Gynecol 2001; 18: 186-7. [CrossRef]

7. Jequier S, Hanquinet S, Bugmann P, Pfizenmaier M. Antenatal small-bowel volvulus without malrotation: ultrasound demonstration and discussion of pathogenesis. Pediatr Radiol 2003; 33: 263-5. [CrossRef]

8. Biyyam DR, Dighe M, Siebert JR. Antenatal diagnosis of intestinal malrotation on fetal MRI. Pediatr Radiol 2009; 39: 847-9. [CrossRef]

9. Schwartzberg D, Burjonrappa SC. Pseudo double bubble: jejunal duplication mimicking duodenal atresia on prenatal ultrasound. J Neonatal Surg 2013; 2: 42.

10. Nakazawa N, Okazaki T, Miyano T. Prenatal detection of isolated gastric duplication cyst. Pediatr Surg Int 2005; 21: 831-4. [CrossRef]

11. Tseng JJ, Chou MM, Ho ES. In utero sonographic diagnosis of a communicating enteric duplication cyst in a giant omphalocele. Prenat Diagn 2001; 21: 540-2. [CrossRef]

12. Laje P, Flake AW, Adzick NS. Prenatal diagnosis and postnatal resection of intraabdominal enteric duplications. J Pediatr Surg 2010; 45: 1554-8. [CrossRef]

13. Valladares E, Rodriguez D, Vela A, Cabre S, Lailla JM. Meconium pseudocyst secondary to ileum volvulus perforation without peritoneal calcification: a case report. J Med Case Rep 2010; 4: 292. [CrossRef]

14. Noreldeen SA, Hodgett SG, Venkat-Raman N. Midgut volvulus with hemorrhagic ascites: a rare cause of fetal anemia. Ultrasound Obstet Gynecol 2008; 31: 352-4. [CrossRef]

15. Tan RM, Lee J, Biswas A, Amutha C. Ascites, anemia and (intestinal) atresia. J Perinatol 2014; 34: 78-80. [CrossRef]

16. Leung WC, Pandya P, Seaward G, Windrim R, Ryan G. Changes in fetal heart rate pattern after intrauterine paracentesis in one twin with meconium peritonitis. Prenat Diagn 2001; 21: 693-6. [CrossRef]

17. Miyakoshi $\mathrm{K}$, Ishimoto $\mathrm{H}$, Tanigaki S, Minegishi $\mathrm{K}$, Tanaka M, Miyazaki T, et al. Prenatal diagnosis of midgut volvulus by sonography and magnetic resonance imaging. Am J Perinatol 2001; 18: 447-50. [CrossRef]

18. Kornacki J, Czarnecka M, Blaszczynski M, Skrzypczak J, Gadzinowski J, Jankowski A, et al. Congenital midgut volvulus associated with fetal anemia. Fetal Diagn Ther 2010; 28: 119-22. [CrossRef]

19. Norris MC, Joseph J, Leighton BL. Anesthesia for perinatal surgery. Am J Perinatol 1989; 6: 39-40. [CrossRef]

20. Langer JC, Tabb T, Thompson P, Paes BA, Caco CC. Management of prenatally diagnosed tracheal obstruction: access to the airway in utero prior to delivery. Fetal Diagn Ther 1992; 7: 12-6. [CrossRef]

21. Zerella JT, Finberg FJ. Obstruction of the neonatal airway from teratomas. Surg Gynecol Obstet 1990; 170: 126-31.

22. Mychaliska GB, Bealer JF, Graf JL, Rosen MA, Adzick NS, Harrison MR. Operating on placental support: the ex utero intrapartum treatment procedure. J Pediatr Surg 1997; 32: 227-30; discussion 30-1. [CrossRef]

23. Ruiz MJ, Thatch KA, Fisher JC, Simpson LL, Cowles RA. Neonatal outcomes associated with intestinal abnormalities diagnosed by fetal ultrasound. J Pediatr Surg 2009; 44: 71-4; discussion 4-5. [CrossRef] 